\title{
Enhancement of gain using a multilayer superstrate metasurface cell array with a microstrip patch antenna
}

\author{
Ali Khalid Jassim¹, Malik Jasim Farhan², Fadia Noori Hummadi Al-Nuaimy ${ }^{3}$ \\ ${ }^{1,2}$ Department of Electrical Engineering, College of Engineering, Mustansiriya University, Baghdad, Iraq \\ ${ }^{3}$ Biomedical Engineering Department, University of Baghdad, Baghdad, Iraq
}

\begin{tabular}{l} 
Article Info \\
\hline Article history: \\
Received Feb 4, 2021 \\
Revised Oct 29, 2021 \\
Accepted Nov 3, 2021 \\
\hline Keywords: \\
Metamaterial \\
Microstrip antenna \\
Multi-layer MTM superstrate \\
Superstrate
\end{tabular}

Article Info

Article history

Received Feb 4, 2021

Revised Oct 29, 2021

Accepted Nov 3, 2021

Keywords:

Metamaterial

Multi-layer MTM superstrate

Superstrate

\begin{abstract}
This research presents a new idea in the use of wireless communication antennas: it uses a multi-layered array of cells called a superstrate multi-layer metasurface (MTM) and is placed in front of a patch of microstrip antenna to absorb surface waves and prevent them from passing through the insulating material, which reduces the permeability of the insulator and thus improves the Antenna properties, The proposed hexagonal cell with resonators is placed on the flame resistant (FR4) substrate, with a relative permittivity of 4.3 and an area $(14 \times 14) \mathrm{mm}^{2}$. It was tested when the metasurface layer is $4 \mathrm{~mm}$ in front of the patch and the distance between the metasurface layers is $2 \mathrm{~mm}$. The optimum distances were calculated by the sweep parameter, and the improved antenna gain and the input reflection coefficient were obtained together. (S11) has been improved from -31.217 to $-38.338 \mathrm{~dB}$ and, the gain from $3.28 \mathrm{~dB}$ to $6.554 \mathrm{~dB}$.
\end{abstract}

This is an open access article under the CC BY-SA license.

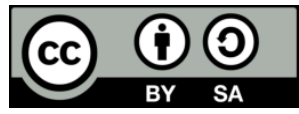

\section{Corresponding Author:}

Ali Khalid Jassim

Department of Electrical Engineering, College of Engineering

Mustansiriya University

Baghdad, Iraq

Email: alijassim79@yahoo.com

\section{INTRODUCTION}

Small planar antennas have a low gain, which must be resolved in order to meet the maximum energy budget of transceiver systems. A metamaterial is a material that has been employed in the design of antennas in addition to using an array antenna. Artificial magnetic materials (AMMs) could be used in this situation. They are used in the antenna's environment by arranging the metamaterials unit cells about the antenna's radiated elements [1]-[3], or by creating a superstructure above or below the radiated parts [4]-[6], or by using metamaterials as the antenna's loading [7]-[10]. Figure 1 depicts how metamaterials have been used as a superstrate to improve antenna gain.

Each of these techniques has its own set of benefits and drawbacks. The number of metasurface layers, the distance between them, the shape of the single cell, the distance between the cell parts that form resonance, and the radiation elements significantly affect the antenna power gain [11]-[14]. The position of the metasurface layer and the number of cells forming the array in front of or behind the bag also has a great effect on the antenna properties, especially the gain, and the number of single cells and the resonant frequency of the built-in antenna affect the gain value [15]-[17]. Artificial magnetic conductors (AMCs) or AMMs are generated by these array unit cells, and they can be loaded on one or both sides of the superstrate. The number of superstrates, unit cells, and distance between the radiation element and the superstrate decide the antenna's power gain [18], [19]. 


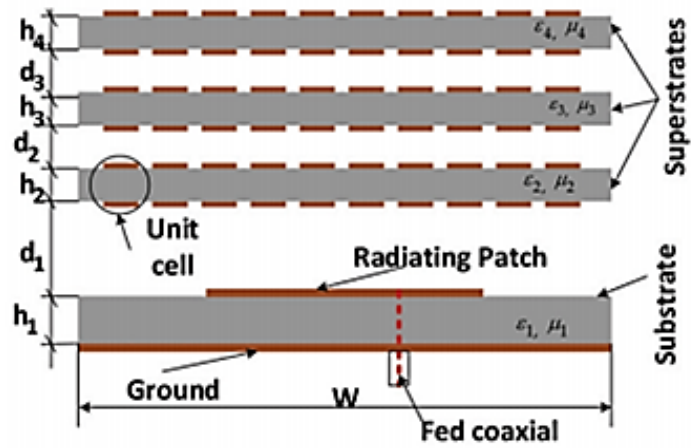

Figure. 1. Metamaterials used as a superstrate to increase the antenna gain

\section{DESIGN OF THE METASURFACE UNIT CELL}

Two symmetrically arranged hexagonal shaped split ring resonators make up the proposed metamaterial unit cell pentagonal short-range reconnaissance (SRR). The proposed pentagonal SRR's comprehensive dimension structure is shown in Figure 2. A capacitor can be used to depict the separation distance in hexagonal shape patches. The capacitor, on the other hand, fills the gap in the hexagonal shape sides. An inductor provides the conductor bar in the hexagonal shape section. The free space impedance (377) is used to calculate the load resistance [20]-[26]. Figure 3 shows $\left(\mathrm{s}_{11}\right)$ for the unit cell of metasurface proposed.

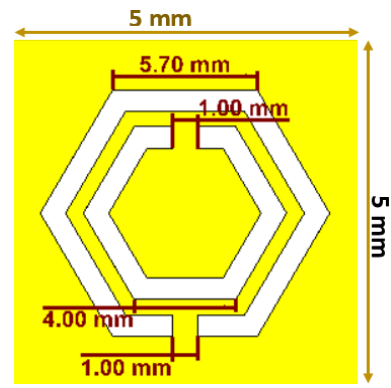

(a)

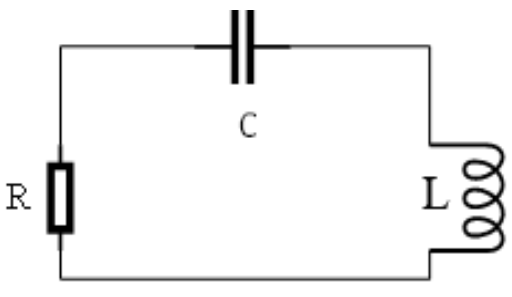

(b)

Figure 2. The hexagonal of (a) cell proposed and (b) cell proposed of equivalent circuit

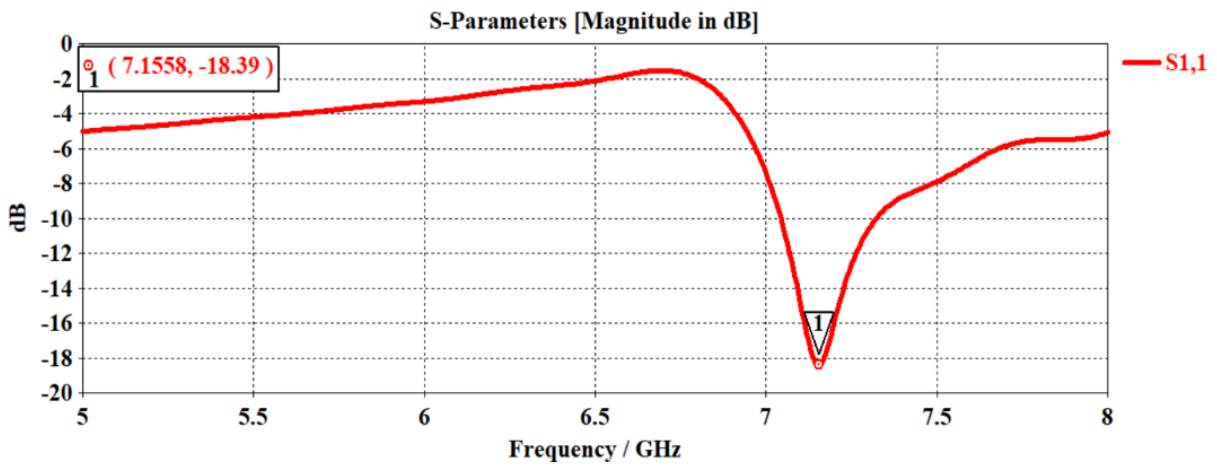

Figure 3. $\left(\mathrm{S}_{11}\right)$ of unit cell metasurface

\section{MICROSTRIP ANTENNA DESIGN}

This antenna consists of three layers, a patch, operates at a frequency of $7.26 \mathrm{GHz}$, flame resistant (FR4) dielectric substrate with a relative permittivity of 4.3 and a thickness of $1.6 \mathrm{~mm}$, and ground plane. Figure 4 shows the antenna's design parameters. The dimensions that are mentioned in Figure 4 is shown in Table 1. When the microstrip antenna was measured at $7.26 \mathrm{GHz}$ the input reflection coefficient (S11) of the $-31.217 \mathrm{~dB}$, and the microstrip antenna gain at the same frequency is $3.28 \mathrm{~dB}$ as shown in Figures 5 and 6. 


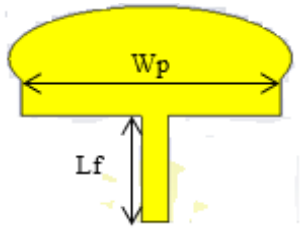

(a)

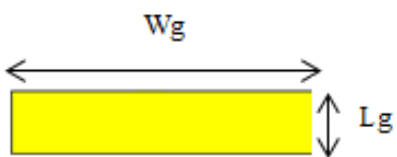

(b)

Figure 4. The proposed of (a) front patch antenna and (b) ground plane for antenna

Table 1 . The designed microstrip antenna's dimensions

\begin{tabular}{clc}
\hline Symbol & \multicolumn{1}{c}{ Quantity } & Value $(\mathrm{mm})$ \\
\hline $\mathrm{L}_{\mathrm{g}}$ & Ground plane length & 3 \\
$\mathrm{~W}_{\mathrm{g}}$ & Ground plane width & 12 \\
$\mathrm{~h}_{\mathrm{t}}$ & Copper thickness & 0.035 \\
$\mathrm{~L}_{\mathrm{s}}$ & Substrate length & 28.51 \\
$\mathrm{~h}_{\mathrm{s}}$ & Substrate height & 1.6 \\
$\mathrm{~W}_{\mathrm{s}}$ & Substrate width & 33.79 \\
$\mathrm{~L}_{\mathrm{f}}$ & Feed line length & 4.13 \\
$\mathrm{~W}_{\mathrm{f}}$ & Feed line width & 2 \\
$\mathrm{Wp}$ & Patch plan width & 12 \\
\hline
\end{tabular}

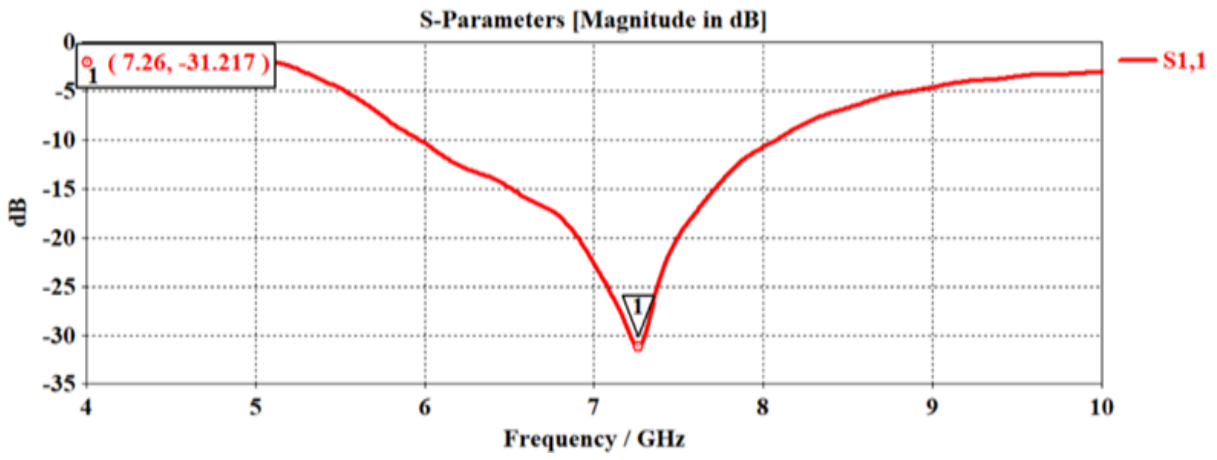

Figure $5 . \mathrm{S}_{11}$ of proposed antenna

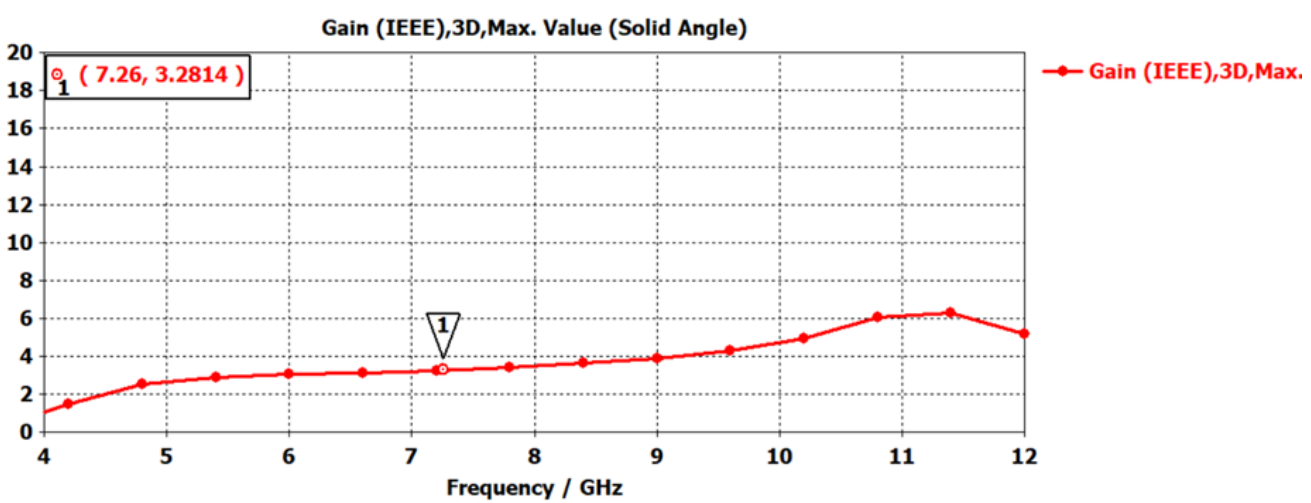

Figure 6. Proposed microstrip antenna gain

\section{SUPERSTRATE ANALYSIS OF MULTI-LAYER METAMATERIALS}

This section introduces a new idea for using a metasurface as a multilayer superstrate and found it in a positive and effective manner. The metasurface of superstrate is composed of a $(2 \times 2)$ cells of hexagonal shape unit cells and has a total area of $(28 \times 28) \mathrm{mm}^{2}$. This number of unit cells was chosen because the area of a loaded antenna must be the same or smaller than the patch area, as shown in Figure 7(a). A multi-layer superstrate with the suggested antenna is displayed in Figure 7(b). The suggested antenna was analyzed using the CST microwave studio package. 


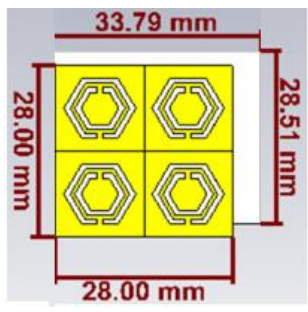

(a)

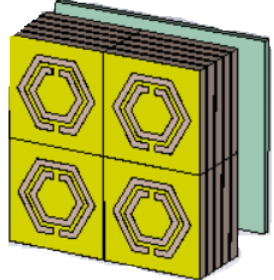

(b)

Figure 7. The unit cell array (a) geometrical structure of the multi-layer metasurface (MTM) superstrate and (b) side view

\section{PARAMETRIC STUDY}

The sweep parameter features in the CST software, which selects the ideal values for the antenna elements, is used to generate the best designs that give the highest improvement in the matching impedance resonance and the gain of the microstrip antenna. Figure 8 show the $S_{11}$ of the proposed patch antenna at a different space between the layers and a patch. The distance to reach the optimal result after examining the parametric study results for the maximum input reflection coefficient and the gain is $d=4$ and the distance between layers is $2 \mathrm{~mm}$ as shown in Figures 9 and 10. The position of the metasurface layers is optimized to enhanced the input reflection coefficient as shown in Figure 9, (S11) parameter was equal to $-38.338 \mathrm{~dB}$, it validated to be more than $(10 \mathrm{~dB})$ indicating good antenna matching.

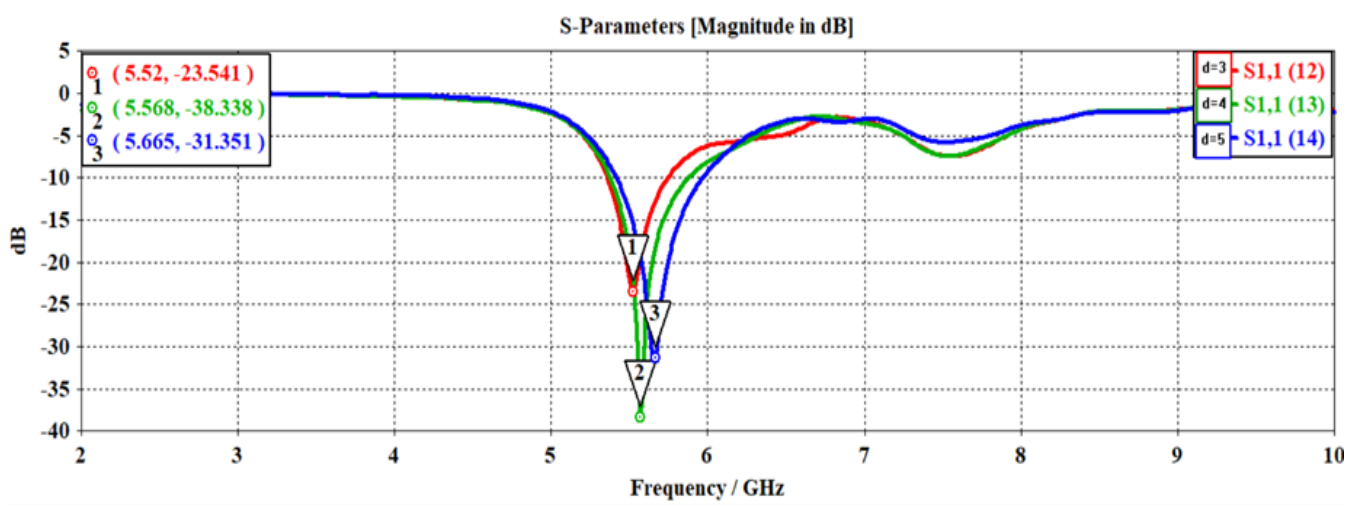

Figure 8. Input reflection coefficient parametric analysis for various distances

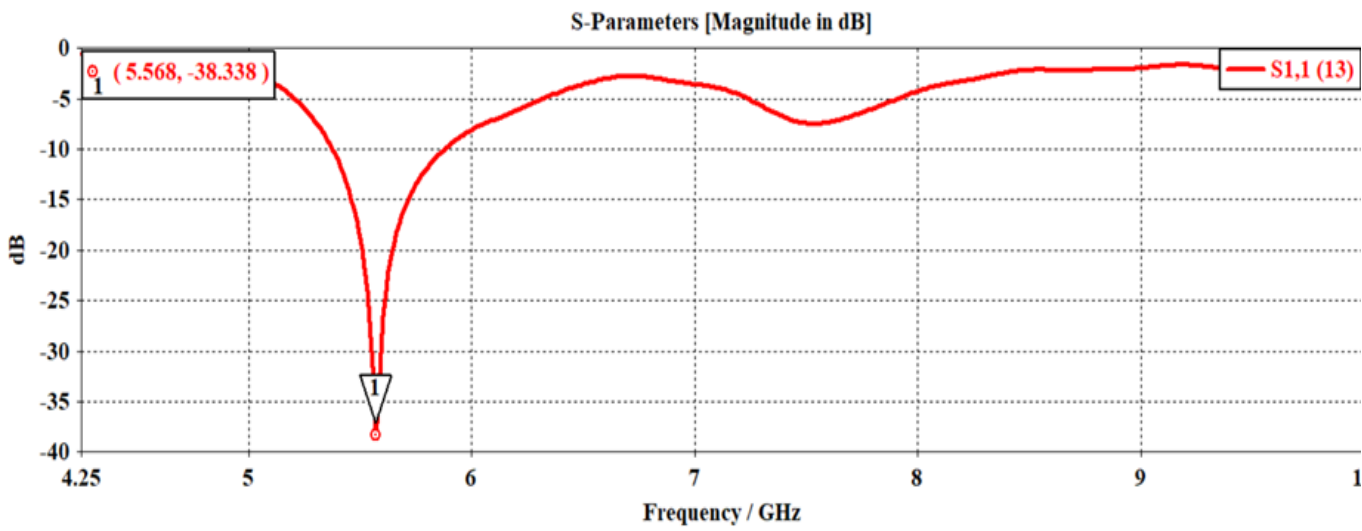

Figure 9. $\left(\mathrm{s}_{11}\right)$ at a distance of $4 \mathrm{~mm}$

The proposed antenna gain enhancement can be described using Snell's law of refraction, whereby electromagnetic waves are transmitted in the direction of the surface standard by and away from the source

Enhancement of gain using a multilayer superstrate metasurface cell array with ... (Ali Khalid Jassim) 
where it is a material with a low refractive index. The field distribution of the antenna is also affected by the presence of an MTM superstrate. One of the most important features is to improve the gain of the microstrip antenna, in this case, is enhanced as shown in Figure 10. Figure 11 is shown voltage standing wave ratio (VSWR) was calculated and validated to be less than 2, indicating that the antenna matching was satisfactory because VSWR is a measurement of the mismatch between the antenna and the feeding system. Larger the mismatch, the higher the VSWR. The smallest value of VSWR is unity, which results in a perfect match. The proportion of maximum to minimum voltages is referred to as VSWR.

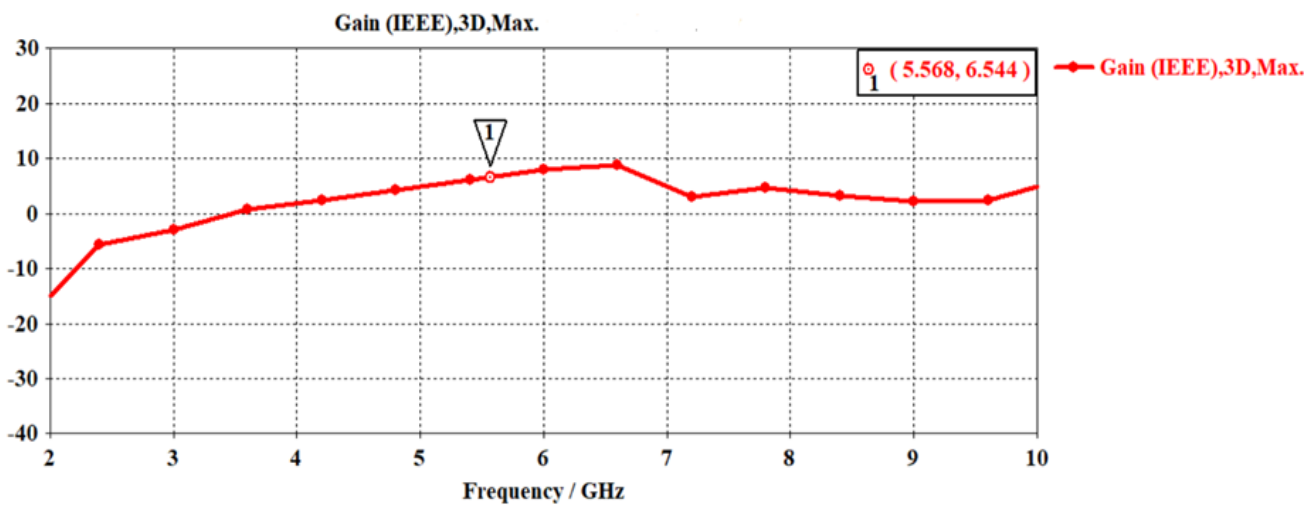

Figure 10. The gain for proposed antenna with multi-layer superstrate

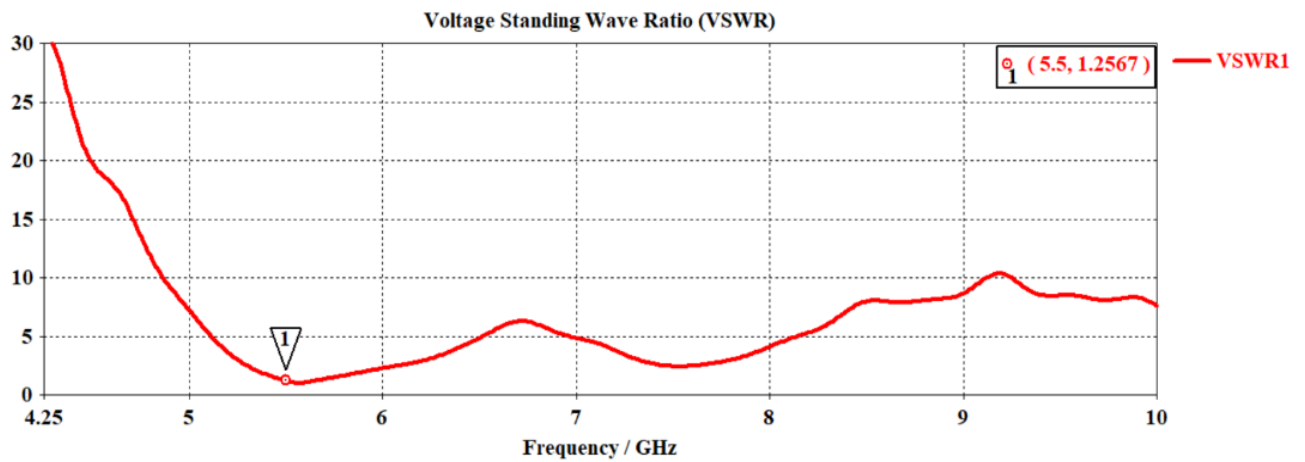

Figure.11. VSWR at the distance $4 \mathrm{~mm}$

When the metasurface is applied over the microstrip antenna patch, we observe a frequency shift when the dielectric property of the substrate is changed as shown in the (1),

$$
f_{r}=\frac{f_{o}}{\sqrt{\varepsilon_{r}}}
$$

where, $\mathrm{f}_{0}$ is operating of frequency $(\mathrm{GHz}), \mathrm{f}_{\mathrm{r}}$ is resonant of frequency $(\mathrm{GHz})$, and $\varepsilon_{\mathrm{r}}$ is relative of permittivity Table 2 compares the proposed antenna without a metasurface to the proposed one with a multi-layer metasurface.

Table 2. Comparison between characteristics antennas

\begin{tabular}{lccc}
\hline Case of antenna & Frequency $(\mathrm{GHz})$ & Input reflection coefficient value $(\mathrm{dB})$ & Gain value $(\mathrm{dB})$ \\
\hline Without metasurface & 7.26 & -31.217 & 3.28 \\
With a multi-layer metasurface & 5.5 & -38.338 & 6.544 \\
\hline
\end{tabular}

\section{CONCLUSION}

One of the most important conclusions that have been reached when using a metasurface with the antenna is the significant improvement in the antenna properties, including the growth of reflection coefficient and the gain, as well as the number and shape of the metasurface cells, the distance between the components of the unit cell and the distance between the cells forming the array has a significant impact on 
the properties of the antenna and the location of the metasurface in front of the patch or ground also has an effect on the gain as a multi-layer MTM superstrate layer has been developed on the microstrip antenna patch. For the purpose of wireless communication, the hexagonal cells are placed on a FR-4 substrate with a total area of $(14 \times 14) \mathrm{mm}^{2}$. The MTM substrate layers are in front of the patch and the metasurface layer is 4 $\mathrm{mm}$ apart and the distance between the super layers is $2 \mathrm{~mm}$. The antenna gain and reflection coefficient are increased together. $\left(\mathrm{S}_{11}\right)$ was improved from $-31.217 \mathrm{~dB}$ to $-38.338 \mathrm{~dB}$ and the gain was improved to $6.544 \mathrm{~dB}$.

\section{ACKNOWLEDGEMENTS}

The authors extend their thanks to the College of Engineering, Mustansiriyah University, for its assistance and sponsorship of the research.

\section{REFERENCES}

[1] X. Gao, T. Cai, and L. Zhu, "Enhancement of gain and directivity for microstrip antenna using negative permeability metamaterial," Int. J. Math. Comp. Sci., vol. 70, no. 7, pp. 880-885, 2016, doi: 10.1016/j.aeue.2016.03.019.

[2] D. Kim and J. Choi, "Analysis of antenna gain enhancement with a new planar metamaterial superstrate: An effective medium and a fabry-pérot resonance approach," Journal of Infrared, Millimeter, and Terahertz Waves, vol. 31, no. 11, pp. 1289-1303, 2010, doi: 10.1007/s10762-010-9712-2.

[3] P. J. F. Gonzalez, "Multifunctional metamaterial designs for antenna applications," PhD Thesis, Department of Signal Theory and Communications, Universitat Politecnica de Catalunya, Barcelona, Spain, 2015.

[4] H. Mosallaei and K. Sarabandi, "Design and Modeling of Patch Antenna Printed on Magneto-Dielectric EmbeddedCircuit Metasubstrate," IEEE Tran. Ant. Pro., vol. 55, no. 1, pp. 45-52, 2007, doi: 10.1109/TAP.2006.886566.

[5] R. Grimberg, "Electromagnetic metamaterials," Materials Science and Engineering: B, vol. 178, no. 19, pp. 1285-1295, 2013, doi: 10.1016/j.mseb.2013.03.022.

[6] C. Caloz, A. Sanada, and T. Itoh, "A novel composite right-/left-handed coupled-line directional coupler with arbitrary coupling level and broad bandwidth," in IEEE Transactions on Microwave Theory and Techniques, vol. 52, no. 3, pp. 980-992, March 2004, doi: 10.1109/TMTT.2004.823579.

[7] Y. Liu, X. Guo, S. Gu, and X. Zhao, "Zero index metamaterial for designing high-gain patch antenna," International Journal of Antennas and Propagation, 2013, doi: 10.1155/ 2013/215681.

[8] T. N. Cao and W. J. Krzysztofik, "Multiband fractal antenna for C-band ground station of satellite TV in ITU region-3," 21st Int. Conf. Micro., Rad. Wir. Comm., 2016, pp. 1-4, doi: 10.1109/MIKON.2016.7491946.

[9] F. Raval, Y. P. Kosta, and H. Joshi, "Reduced size patch antenna using complementary split ring resonator as defected ground plane," Int. J. Elec. Comm., vol. 69, no. 8, pp. 126-1133, 2015, doi: 10.1016/j.aeue.2015.04.013.

[10] R. Rajkumar and K. U. Kiran, "A compact metamaterial multiband antenna for WLAN/WiMAX/ ITU band applications," AEU - Int. J. Elec. Comm., vol. 70, no. 5, pp. 599-604, 2016, doi: 10.1016/j.aeue.2016.01.025.

[11] A. A. Jabber, A. K. Jassim, and R. H. Thaher, "Compact reconfigurable PIFA antenna for wireless applications," TELKOMNIKA Telecommunication Computing Electronics and Control, vol. 18, no. 2, pp. 595-602, 2020, doi: 10.12928/telkomnika.v18i2.13427.

[12] Z. Szabó, G. Park, R. Hedge, and E. Li, "A Unique Extraction of Metamaterial Parameters Based on Kramers-Kronig Relationship," IEEE Tran. Micro. The. Tech., vol. 58, no. 10, pp. 2646-2653, 2010, doi: 10.1109/TMTT.2010.2065310.

[13] A. Benedetti, C. Sibilia, and M. Bertolotti, "Wideband negative magnetic permeability materials (NMPM) with composite metal-semiconductor structures based on the Drude model, and applications to negative-refractive index (NIM)," Opt. Express, vol. 15, no. 11, pp. 6534-6545, 2007, doi: 10.1364/OE.15.006534.

[14] J. B. Pendry, A. J. Holden, D. J. Robbins, and W. J. Stewart, "Low-frequency plasmons in thin-wire structures," J. Phys. Condens. Matter, vol. 10, no. 22, 1998, doi: 10.1088/0953-8984/10/22/007.

[15] J. B. Pendry, A. J. Holden, W. J. Stewart, and I. Youngs, "Extremely low-frequency plasmons in metallic mesostructures," Phys. Rev. Lett., vol. 76, no. 25, pp. 4773-4776, 1996, doi: 10.1103/PhysRevLett.76.4773.

[16] A. Alu and N. Engheta, "Pairing an epsilon-negative slab with a mu-negative slab: resonance, tunneling and transparency," IEEE Tran. Ant. Pro., vol. 51, no. 10, pp. 2558-2571, 2003, doi: 10.1109/TAP.2003.817553.

[17] D. R. Smith, D. C. Vier, T. Koschny, and C. M. Soukoulis, "Electromagnetic parameter retrieval from inhomogeneous metamaterials," Phys. Rev. E, vol. 71, no. 3, 2005, doi: 10.1103/PhysRevE.71.036617.

[18] A. K. Jassim, M. J. Farhan, and A. F. Fahad, "Design selective band antenna using coupling sidewall and multi resonator for wireless communications," Bulletin of Electrical Engineering and Informatics, vol. 9, no. 5, pp. 2206-2212, 2020, doi: 10.11591/eei.v9i5.2247.

[19] J. Baker-Jarvis, E. J. Vanzura, and W. A. Kissick, "Improved technique for determining complex permittivity with the transmission/reflection method," in IEEE Transactions on Microwave Theory and Techniques, vol. 38, no. 8, pp. 1096-1103, Aug. 1990, doi: 10.1109/22.57336.

[20] X. Chen, T. M. Grzegorczyk, B-I. Wu, J. Pacheco, and J. A. Kong, "Robust method to retrieve the constitutive effective parameters of metamaterials," Phys. Rev. E, vol. 70, no. 1, 2004, doi: 10.1103/PhysRevE.70.016608.

[21] H. A. Majid, M. K. A. Rahim, and T. Masri, "Left handed metamaterial design for microstrip antenna application," 2008 IEEE International RF and Microwave Conference, 2008, pp. 218-221, doi: 10.1109/RFM.2008.4897426.

[22] G. Kiziltas and J. L. Volakis, "Miniature antenna designs on metamaterial substrates," 8th Int. Conference on Electromagnetics in Advanced Appl. (ICEAA), Conf. Proceedings, 2003, pp. 431-434. 
[23] Y. Dong and T. Itoh, "Metamaterial-Based Antennas," in Proceedings of the IEEE, vol. 100, no. 7, pp. 2271-2285, July 2012, doi: 10.1109/JPROC.2012.2187631.

[24] A. K. Jassim and R. H. Thaher, "Design and analysis microstrip antenna with a reflector to enhancement gain for wireless communication," Bulletin of Electrical Engineering and Informatics, vol. 9, no. 2, pp. 652-660, 2020, doi: 10.11591/eei.v9i2.1696

[25] K. Aydin and E. Ozbay, "Left-handed metamaterial-based superlens for subwavelength imaging of electromagnetic waves," Appl. Phys. A, vol. 87, no. 2, pp. 137-141, 2007, doi: 10.1007/s00339-006-3817-4.

[26] R. M. Salih and A. K. Jassim, "Microstrip patch antenna with metamaterial using superstrate technique for wireless communication," Bulletin of Electrical Engineering and Informatics, vol. 10, no. 4, pp. 2055-2061, 2021, doi: 10.11591/eei.v10i4.2722.

\section{BIOGRAPHIES OF AUTHORS}
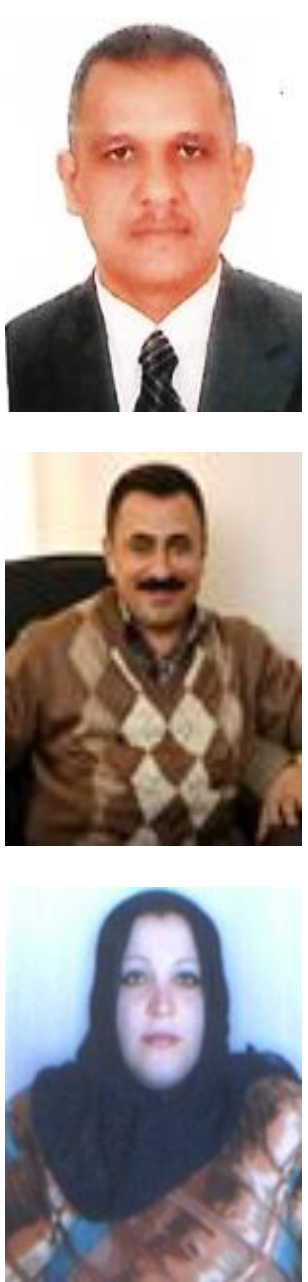

Asst. Prof. Dr. Ali Khalid Jassim: at Mustansiriyah University, college Engineering of Electrical Engineering Department. Holds a Bachelor's degree in 1999 and a Master's degree in 2010 and a Ph.D. in 2019 in communications engineering. Works in the field of cellular networks communications and antennas and has a many of research in international journals and scientific conferences. E-mail: alijassim79@yahoo.com; alijassim@uomustansiriyah.edu.iq

Asst. Prof. Dr. Malik Jassim Farhan at Mustansiriyah University, College of Engineering, held the position of Head of the Electrical Engineering Department in 2018 and became the Dean of the College of Engineering in 2019. He obtained a bachelor's degree in 1997, a master's degree in 2000 , and a doctorate in 2015 , specializing in communications engineering, and he works in the field of antennas. A large number of research published in international journals and conferences. E-mails: malikjf1974@gmail.com; malik.jasim@uomustansiriyah.edu.iq

Fadia Noori Hummadi Al-Nuaimy was born on 26th February, 1969, in Baghdad, Iraq. She received the M.Sc. degree in electronics and communications engineering from the College of Engineering at Mustansiriyah University in 2010, and got the B.Sc. degree in electrical engineering from the College of Engineering at the University of Baghdad in 1991. She is a one of the academic staff members at Al-Khwarizmi Collage of Engineering, University of Baghdad. She published many books and researches in electronics, and communications. E-mail: fadianoori1969@gmail.com; fadia@kecbu.uobaghdad.edu.iq 